DOI: https://doi.org/10.14232/actahisp.2021.0.21-29

\title{
COMPOSTOS SUBSTANTIU + ADJECTIU (TIPUS ULLNEGRE) EN CATALÀ I ALTRES LLENGÜES IBEROROMÀNIQUES
}

\author{
ILDIKó SZIJJ
}

Universitat Eötvös Loránd de Budapest

\begin{abstract}
Resum: L'objectiu de l'article és comparar la productivitat i altres característiques dels compostos adjectivals del tipus ullnegre en català, espanyol, portuguès i gallec. Els elements procedeixen de diccionaris monolingües. El resultat de la comparació és que aquest tipus de composició és més freqüent en català i en espanyol, mentre que és esporàdic en portuguès i en gallec. L'estructura dels mots divergeix en català de les altres llengües, per no contenir la vocal d'enllaç $i$.
\end{abstract}

Paraules clau: compostos substantiu + adjectiu, català i altres llengües iberoromàniques, vocal d'enllaç en mots compostos.

Abstract: The aim of this paper is to compare the productivity and other characteristics of adjectival compounds (like ullnegre) in Catalan, Spanish, Portuguese and Galician. The elements were taken of monolingual dictionaries. The result of the comparison is that this type of composition is more frequent in Catalan and Spanish and sporadic in Portuguese and Galician. The structure of the words in Catalan is different from the other languages, because they don't have the joining vowel $i$.

Keywords: Noun + Adjective Compounds, Catalan and Other Ibero-Romanic Languages, Joining Vowel in Compound Words.

\section{Introducció}

Aquest article té l'objectiu d'observar els compostos adjectivals catalans del tipus ullnegre i comparar aquest procés de formació de mots amb el castellà, el portuguès i el gallec. Existeixen compostos semblants en les quatre llengües: cat. ullnegre, esp. pelirrojo, port. boquiaberto, gal. barbilouro, però sembla que el grau de productivitat i altres característiques d'aquest tipus de composició no són homogenis en les quatre llengües.

Tindré en compte el material lèxic del Diccionari de la llengua catalana de l'Institut d'Estudis Catalans (2007), del Diccionario abreviado del español actual de Manuel Seco, Olimpia Andrés i Gabino Ramos (2000), del Dicionário da Lingua Portuguesa de la Academia das Ciências de Lisboa (DLPC, 2001) i el Gran diccionario Xerais da lingua (2000).

Descriuré, per tant, els compostos adjectivals del tipus ullnegre, incloent també en el corpus elements com ara alatrencat o bocabadant. En Gràcia (2002: 811) aquests mots apareixen en grups diferents en el subcapítol dels compostos adjectivals, perquè, mentre el primer compost conté un adjectiu com a segon element, els dos últims tenen un 
Compostos substantiu + adjectiu (tipus ullnegre) en català i altres llengües iberoromàniques

participi i un gerundi, respectivament. També considero elements com ara caragirat, participi del verb caragirar, perquè apareix separadament en el diccionari.

El grup de compostos que descriuré té com a primer element un substantiu que designa una part del cos i el segon element indica una característica que es refereix al substantiu. Els compostos que descriuré presenten característiques comunes amb altres compostos, com ara drogoaddicte, fefaent (Gràcia, 2002: 811), aireferit, creuclavat, gelcuit, llampferit, solcuit (Bruguera, 2006: 28), que aquí no tindré en consideració.

El nom que apareix en primera posició és un nom de possessió inalienable (Gràcia, 2002: 811), per això normalment és un substantiu que designa una part del cos (Bruguera, 2006: 28) i l'adjectiu compost sol aplicar-se a éssers animats (humans i animals). També pot aplicar-se a plantes o éssers inanimats (fullagroc, aiguamoix), però en aquest cas té valor de substantiu.

Aquests compostos són endocèntrics (Gràcia, 2002: 813), amb el nucli en segona posició, p. ex. camacurt pot tenir la paràfrasi "curt de cames". La paràfrasi, tanmateix, no és possible si el compost té sentit figurat (a panxacontent no hi pot correspondre * content de panxa). Lang (1992: 110) considera que en aquests casos els compostos són exocèntrics. També són clarament exocèntriques les variants dialectals del baleàric, en què el segon element concorda amb el primer element del compost: Sa nina està capbaix. S'al'lot és un llenguallarga (Gràcia, 2002: 812). Aquests compostos s'assemblen a d'altres en què hi ha concordança entre els dos elements, com ara pellroja, casc blau (substantius). No tindré en compte aquestes variants dialectals.

Bruguera (2006: 28) destaca que aquest tipus de compostos (substantiu + adjectiu / participi) és el més productiu en català, juntament amb els compostos formats amb verb més substantiu (com ara trencanous). Segons Gràcia (2002: 812) els compostos substantiu + adjectiu que tenen com a segon element un adjectiu o un participi són més productius, mentre que ho són menys els que contenen un adjectiu deverbal en -nt (com ara bocabadant).

En el cas de l'espanyol, Val Álvaro (1999: 4813) inclou aquest tipus de compost en el subgrup "compuestos formados por nombre y adjetivo con vocal de enlace", perquè els dos elements dels compostos espanyols es lliguen mitjançant la vocal $i$, p. ex. pelirrojo. En aquesta llengua, per tant, el substantiu perd la seva vocal final, la vocal temàtica -o, $a$, - $e$ i l'adjectiu s'afegeix a l'arrel seguida per la vocal $i$ : p. ex. pel-, car-, carn-formen els compostos pelirrojo, carirredondo, carniseco. En els exemples que hem donat al començament per al portuguès $\mathrm{i}$ per al gallec trobem la mateixa estructura: port. boquiaberto, gal. barbilouro. La vocal d'enllaç $i$ apareix també en altres tipus de composició, p. ex. esp. agridulce, clarividente, etc., en català també és present en alguns casos, p. ex. clarivident, compost culte.

Lang (1992: 110) destaca que els compostos adjectivals espanyols formats per aquest procediment tenen sovint significat pejoratiu.

Segons Aguirre (2013: 195) aquest tipus de compost ve directament del llatí, que alternava l'ordre $\mathrm{N}+\mathrm{A}$ (barbirasus) amb $\mathrm{A}+\mathrm{N}$ (longimanus). Alguns compostos cultes, 
com ara rectilini o curvilini, conserven l'ordre $\mathrm{A}+\mathrm{N}$. Destaquem el mot grandirostre, que indica la qualitat d'una part del cos, com els elements que examinem en aquest article. Aquests compostos amb ordre $\mathrm{A}+\mathrm{N}$ tenen vocal d'enllaç $i$ també en català.

\section{Compostos iberoromànics}

\subsection{Compostos catalans}

A continuació dono la llista dels compostos que apareixen en el diccionari català utilitzat com a corpus. Els enumero per ordre alfabètic, $\mathrm{i}$ si tenen un significat transparent, no en dono cap altra informació (p. ex. alablanc). Per contra, hi indico si poden tenir sentit figurat (p. ex. alatrencat) o només tenen sentit figurat (p. ex. ancarossegant) o si s'apliquen a una categoria semàntica especial (p. ex. bocafresc). També hi faig constar el significat quan és imprevisible (p. ex. barra-ample). Alguns elements poden ser adjectius i al mateix temps substantius, en el darrer cas també tenen un significat imprevisible (p. ex. ala-roig). Poso entre parèntesis els compostos que només tenen la categoria de substantiu, perquè queden fora de l'àmbit principal d'aquest estudi (p. ex. becplaner). En el número final dels elements només tinc en compte els adjectius.

No incloc p. ex. el compost camatrencat, perquè no apareix en el diccionari de forma independent, només hi trobem el verb camatrencar.

1. alabaix, alablanc, alablau, alacaigut (també fig.), alaestès, alaferit, alallarg, alalligat, alapintat, ala-roig (també subst., tipus de peix), alatrencat (també fig.)

2. anca-rossegant (fig.)

3. banyabaix (també fig.), banyadaurat

4. barbablanc, barbaclar, barbaclòs, barbaespès, barbaflorit, barbafort, barbafresc, barbagrís, barbamec, barbanegre, barbapunyent, barba-reveixi, barba-roig (també subst., tipus d'ocell), barba-ros, barba-serrat

5. barra-ample ('que menja molt', s'aplica a un bou, una vaca, etc.), barraprim ('que menja poc', s'aplica a un bou, una vaca, etc.), barra-sec

6. becfí, becgroc, becgròs (també subst.,'durbec' tipus d'ocell), becllarg, (becplaner subst., tipus d'ocell; bectort, subst., tipus d'ocell) becvermell (també subst., tipus d'ànec)

7. bocaample, bocabadant (també fig.), bocabadat (també fig, amb adjectiu, p. ex. bocabadat bru, tipus de bolet), bocaclòs, (bocadolc(a) subst., tipus de peix) bocadur (s'aplica a un cavall, a un mul, etc.), bocaestret, bocafi (fig.), bocafluix (fig.), bocafort (s'aplica a un cavall, a un mul, etc.), bocafresc (s'aplica a un cavall, a un mul, etc.), bocagròs (s'aplica a un cavall, a un mul, etc.), bocamoll (s'aplica a un cavall, a un mul, etc.; fig.), bocanegre (s'aplica principalment al cavall), boca-rugat, boca-sec (també 'que té la boca no gens dòcil al fre', s'aplica a un cavall, a un mul, etc.), bocaterrós ('de boca a terra'), bocatort

8. cabellblanc 
Compostos substantiu + adjectiu (tipus ullnegre) en català i altres llengües iberoromàniques

9. (camabruna, subst., tipus de planta) camacoix (també fig.), camacurt (camagroc subst., tipus de bolet), camallarg (també subst., tipus d'ocell; camallarga, tipus d'ocell), camalluent (fig., 'pagès'), camanegre, camaobert, camaprim, (cama-roig, subst., tipus d'ocell, tipus de planta) (cama-sec subst., tipus de bolet, cama-seca subst., tipus d'ocell, tipus de bolet) cama-segat (fig., 'cansat'), camatort

10. capalt, capbaix, capblanc, (capblau subst., planta) capbuit, capcot, capdret, capesflorat (fig.), capfluix (fig.), capgròs (també subst., tipus d'amfibi), capjup, capmoix, capnegre, cap-roig (també subst., tipus de peix), cap-rossenc (capserrat subst., instrument)

11. caraalegre, caraample, carablanc, carabrú, carabrut, carafresc, caragirat (fig.), caragròs, carallarg, caramenut, caranegre, carapigat, caraplè, cara-rodó, cara-roig, cara-rugat, cara-xuclat

12. cellablanc, cellacanut, cellajunt, cellanegre, cella-ros

13. (collblau subst., tipus d'ànec) collestret, collnegre, collpelat, colltort (també fig.), collverd (també subst., tipus d'ànec)

14. cordur (fig.), cor-robat (fig.)

15. cuaample, cuabarrat, cuablanc (també subst., tipus d'ocell), cuacurt, cuadret (també fig.), (cuaenlairat subst., tipus d'ocell) cuafí, cuaforcat, cuallarg (també subst., tipus d'ocell), cuanegre, cuapunxegut, cuaquadrada (en la combinació musaranya cuaquadrada), cua-rogenc, cuaroig (també subst., tipus d'ocell, tipus de peix), cua-rutllat

16. culgròs (també subst., tipus de bolet)

17. esmaperdut

18. esquenadret (fig.), esquena-romput (fig.)

19. frontample

20. galtaplè (galta-roig subst., tipus de peix) (en el diccionari no apareix galta-roig com adjectiu, tot i que hi surt llissa galta-roja)

21. garracurt, garrallarg, garratibat (també fig.)

22. golanegre, gola-roig

23. gorjablanc (també subst., tipus d'animal), gorjagroc (també subst., tipus d'animal)

24. llavifes, llavigròs

25. llenguallarg (també subst., tipus d'ocell)

26. mà-llarg

27. morrofes

28. panxabuit, panxacontent (fig.)

29. pèl-blanc, pèl-curt, pèl-llarg, pèl-ras, pèl-roig

30. pengròs, peuterròs (fig.)

31. (pitnegre subst., tipus d'ocell) pit-roig (també subst., tipus d'ocell)

32. ullblau, ullcluc, ullnegre, ullprenedor (ullverd, subst., tipus de peix)

Els substantius que apareixen en els compostos són: ala, anca, banya, barba, barra, bec, boca, cabell, cama, cap, cara, cella, coll, cor, cua, cul, esma, esquena, front, galta, garra, gola, gorja, llavi, llengua, mà, morro, panxa, pèl, peu, pit, ull. No hi ha compostos amb certes parts del 
cos, p. ex. orella, braç, nas, tot i que podríem pensar que, des del punt de vista semàntic, aquestes parts del cos també serien adequades per caracteritzar una persona o un animal.

Per altra banda, els adjectius també són limitats, p. ex. no formen compostos d'aquest tipus adjectius tan freqüents com ara gran, petit. Apareixen p. ex. molts adjectius que indiquen un color (35 casos).

Els substantius designen membres exteriors del cos, visibles, excepte esma (esmaperdut) i un òrgan interior (cor), els compostos formats amb aquest substantiu tenen sentit figurat (cordur, cor-robat).

El substantiu apareix sempre en singular, també en el cas de les parts del cos dobles, com ara ull, cama o peu, p. ex. ullnegre, camacurt, peugròs.

Els compostos normalment tenen un significat transparent: p. ex. alablanc significa 'que té les ales blanques' o 'és blanc pel que fa a les ales'. En bastants casos el sentit és figurat, p. ex. anca-rossegant 'abatut, alacaigut'. També hi ha casos amb significat concret i figurat alhora, p. ex. alatrencat 1 . 'que té rompuda una ala o les ales $\mathrm{i}$ amb dificultat pot volar', 2. 'que no segueix el dret camí, que no fila bé'.

També hi ha compostos del mateix tipus amb funció de substantiu, p. ex. becplaner, pitnegre, ullverd. Molts d'aquests compostos designen un tipus d'ocell (o en concret, un tipus d'ànec) (18), o, en un nombre més reduït de casos, peixos (6), bolets (5) o plantes (3), un amfibi (1), un altre tipus d'animal (1) o un instrument (1). Quan el primer element dels compostos és femení, el segon element pot ser masculí o femení, o sigui pot concordar amb el substantiu. Alguns dels compostos són masculins, d'altres femenins. Vegem-ne tres casos: camagroc $\mathrm{m}$, camabruna $\mathrm{f}$ i camallarga $\mathrm{m}$. El substantiu compost neix per l'el'lipsi d'una combinació de substantiu i adjectiu, l'adjectiu compost (camagroc) originalment modificava un altre substantiu (masculî), i se n'el'lideix el substantiu, p. ex. (bolet) camagroc. El segon compost, camabruna f, seria semblant, la diferència és que el substantiu originalment modificat devia ser femení, p. ex. (planta) camabruna. En el tercer cas, en canvi, hi ha originalment un sintagma nominal amb adjectiu i aquest sintagma es converteix en substantiu. En aquest últim cas, des del punt de vista semàntic, una part del cos (amb adjectiu) per metonímia passa a designar tot l'animal.

Tenint com a criteri si els compostos són transparents o de significat imprevisible, trobem les següents proporcions: entre els 151 adjectius 103 tenen significat transparent, 9 significat transparent i figurat alhora, 14 sentit figurat, 9 són transparents, però només s'apliquen a certs substantius (p. ex. a cavalls), 16 tenen significat transparent $\mathrm{i}$ alhora funció de substantiu amb un significat específic.

\subsection{Compostos espanyols}

En espanyol trobem els següents compostos:

1. aliblanco, alicaído (fig.), alicortado (també fig.), alicorto (també fig.), aliquebrado (també fig.), alirrojo (combinat amb zorzal, ocell) 
Compostos substantiu + adjectiu (tipus ullnegre) en català i altres llengües iberoromàniques

2. astifino (taurom.), astigordo (taurom.), astinegro (taurom.)

3. barbiespeso (rar), barbilampiño, barbilindo (lit., rar, desp.), barbilucio (lit., rar), barbinegro, barbiponiente, barbirrojete (reg., fig. 'casi borracho'), barbirrojo, barbirrucio, barbitabeño (lit.)

4. boquiabierto (també fig.), boquirroto (lit., rar, fig.), boquirrubio (fig., lit., rar), boquisumido (lit.), boquituerto (rar)

5. cabecinegra (combinat amb curruca, gaviota), cabiz̧bajo (també fig.), cabizcaido (rar, també fig.)

6. cariacontecido, cariancho, cariavacado (taurom.), carifosco (taurom.), carinegro (es diu d'un animal, p. ex. barnacla), carininfo (lit., ninfo no existeix com a adjectiu, format a partir del subst. ninfa), carirredondo

7. carniseco

8. cejijunto

9. colilargo, colinegro (es diu d'un ocell), colipavo (combinat amb paloma), colipinto (combinat amb aguja, ocell), colirrojo (combinat amb lagartija, també subst., ocell) (colirrubio, subst., ocell, reg.)

10. corniabierto (taurom.), cornialto (taurom.), corniancho (taurom.), cornicorto (taurom.), cornidelantero (taurom.), cornigacho (taurom.), corniveleto (taurom.), cornivuelto (taurom.)

11. cuellicorto, cuellierguido, cuellinegro (es diu d'un animal), cuellirrojo (es diu d'un animal)

12. culialto (col.), culibajo (col.), culiblanco (es combina amb sacristán, vencejo, ocells)

13. espalditendido (rar)

14. lengüilargo (col., fig.)

15. lomienbiesto (lominhiesto) (rar), lomitendido (taurom.)

16. manicorto (fig.)

17. ojigarzo (lit.), ojijunto (rar), ojinegro, ojituerto (rar), ojizaino (rar), ojizarco (lit.)

18. orejisano (taurom.)

19. papialbo (combinat amb mosquitero, ocell), papirrojo (combinat amb papamoscas)

20. patiabierto (col.), paticojo (col.), paticorto, patidifuso (fig., col.), patinegro (es diu d'un animal), patirrojo, patitieso (col.), patituerto, patizambo

21. (pechiazul subst., ocell; pechirrojo subst., ocell) pechisacado (també fig.)

22. peliagudo (fig.), pelilargo, pelirrojo, pelirrubio, pelitieso

23. (petigrís subst., tipus d'esquirol; petirrojo subst., ocell)

24. pierniabierto, piernicorto, piernilargo

25. piquigualdo, piquirrojo, piquituerto, (picocruzado, subst. ocell) picofino (també subst., ocell), (picogordo subst., ocell) piconegro (sense vocal d'enllaç)

26. rabicorto, rabilargo

27. zanquilargo (col.)

Des del punt de vista de la forma, la principal diferència entre les dues llengües és que la vocal final del substantiu, primer membre del compost espanyol és $i$, o dit d'una altra forma, entre el substantiu i l'adjectiu hi ha una vocal d'enllaç. Comparem els compostos següents: cat. caranegre, esp. carinegro. Les excepcions de l'espanyol són picofino 
i piconegro, on apareix el substantiu amb la seva forma completa. Al mateix temps també existeixen piquigualdo, piquirrojo, etc.

Els substantius que apareixen en els compostos són: ala, asta, barba, boca, cabeza, cara, carne, ceja, cola, cuerno, cuello, culo, espalda, lengua, lomo, mano, ojo, oreja, papo, pata, pecho, pelo, pierna, pico, rabo, zanco. (El substantiu peto apareix en substantius.)

Val Álvaro (1999: 4813-4814) dona una llista de les parts del cos que apareixen en compostos formats per nom i adjectiu. Entre aquestes apareixen elements que no es documenten en el diccionari utilitzat com a corpus, p. ex. anqui-, denti-, teti-, etc. A la llista de Val Álvaro apareix també perni-, però al diccionari només es documenten compostos amb pierni-.

Pel que fa a la freqüència, mentre en català hi ha 32 substantius que designen una part del cos i formen compostos d'aquest tipus, en espanyol n'hi ha 27 (26 amb funció d'adjectiu). El número de compostos (amb funció d'adjectiu) en català era 151, en espanyol 96.

El diccionari espanyol dona en molts casos una informació estilística: en 11 casos rar, en 9 casos lit., en 8 casos col., en 1 cas desp., en 2 casos reg. Si descomptem els elements rars o de valor literari o regional, podem considerar que aquest tipus de composició és poc freqüent.

El compost espanyol té nombroses restriccions, en el sentit que l'adjectiu compost s'utilitza amb certs substantius: en 25 casos amb un nom d'animal concret, p. ex. zorzal alirrojo; referint-se a un toro, p. ex. cariavacado; o a un altre animal, p. ex. patinegro.

El significat és transparent en 52 casos, però només apareix en 32 casos sense cap indicació estilística. En 9 casos té sentit figurat, en 7 casos té sentit transparent i figurat alhora. En 26 casos l'adjectiu compost només apareix amb certs substantius.

Alguns elements són només substantius, que en molts casos designen un tipus d'ocell.

També existeix el substantiu lengualarga, sense vocal $i$. No l'he inclòs en la llista.

Pel que fa al significat, el segon element del mot cariacontecido té significat abstracte, contràriament als altres compostos, en què l'adjectiu indica una característica física.

Pot considerar-se especial el mot carininfo, perquè el segon element no és un adjectiu, sinó un substantiu, ninfa. L'he inclòs a la llista, perquè el compost carininfo / a funciona com a adjectiu, amb forma masculina i femenina. És semblant el mot colipavo/ a, amb la diferència que pava existeix també de forma independent.

Són també especials cabiz̧bajo i cabizcaido, per contenir la variant cabiz- de cabeci-.

En espanyol hi ha altres exemples amb una estructura semblant, en què el primer element no designa una part del cos, com ara puntiagudo. 
Compostos substantiu + adjectiu (tipus ullnegre) en català i altres llengües iberoromàniques

\subsection{Compostos portuguesos}

En portuguès hi ha molt pocs compostos d'aquest tipus.

boquiaberto

cabisbaixo

olbibranco (sinònim: olhalvo)

Es documenta encara barbiponente, però ponente no existeix com a mot independent. El mot cabisbaixo és un hispanisme (DLPC).

Existeixen encara substantius, com en català: boca-negra m (tipus de mico), cara-pálida $\mathrm{m} / \mathrm{f}$, cabeça-dura $\mathrm{m} / \mathrm{f}$, cabeça-leve $\mathrm{m} / \mathrm{f}$, cabeça-rapada $\mathrm{m} / \mathrm{f}$, cabeça-tonta $\mathrm{m} / \mathrm{f}$, olho-grosso $\mathrm{m}$ (tipus d'ocell), olho-verde $\mathrm{m}$ (tipus de tauró), pé leve $\mathrm{m}$, pele-vermelha $\mathrm{m} / \mathrm{f}$, pernilongo / pernalonga $\mathrm{m}$ (tipus d'ocell), perna-lavada $\mathrm{f}$ (tipus d'ocell), perna-vermelha $\mathrm{f}$ (tipus d'ocell).

\subsection{Compostos gallecs}

També hi ha pocs compostos semblants en gallec:

barbilouro, barbinegro, barbirroibo

manicurto (manidextro, amb un llatinisme com a segon element)

pernicurto, pernilongo

Apareixen en el diccionari boquirroto, cabisbaixo, cabiscaído, pelirroxo i patizambo, amb la indicació de paraula "no gallega" (paraules normatives: lingoreteiro, amoucado, roxo, pateño).

Es documenten també bocaaberta, bocanegra, bocapodre, bocarrota, bocatorta (les dues últimes escrites amb minúscules, tipografia que significa que el mot no és estàndard). Aquests compostos són alhora adjectius i substantius (masculins i femenins), l'adjectiu del compost concorda amb el substantiu, el compost és exocèntric, com els compostos pellroja, casc blau, i com les variants del tipus llenguallarga en el dialecte baleàric.

\section{Comparació de les quatre llengües}

La diferència més considerable que hem trobat entre el català, l'espanyol, el portuguès $\mathrm{i}$ el gallec és la freqüència dels compostos del tipus ullnegre. En català i espanyol hi ha molts més elements que no pas en portuguès i gallec. Sembla que en espanyol aquests compostos tenen amb freqüència alguna connotació estilística $\mathrm{o}$ restriccions semàntiques, p. ex. molts dels compostos s'utilitzen referint-se a toros. Per tant la llengua on aquest tipus de compostos és més freqüent i té més vitalitat amb un valor estilístic neutre és el català.

Veiem una altra diferència important en la forma: en català no apareix la vocal $i$ d'enllaç: ullnegre (cf. esp. ojinegro, port./gall. pernilongo). Aquesta discrepància sembla tenir repercussions en la fonètica de les formes. Podem pensar que quan hi ha vocal d'enllaç, el primer element és àton, perquè la forma de la paraula es redueix. Ho podem detectar en portuguès, porque es produeix reducció vocàlica: la vocal tònica del primer element 
dels mots boquiaberto i pernilongo és [u] i [i] respectivament. En olbibranco, olhalvo la vocal és [o], sense reducció vocàlica, perquè apareix en posició inicial absoluta (segons la transcripció fonètica del DLPC). En gallec no existeix el fenomen de la reducció vocàlica, contràriament al portuguès, però els mots pernicurto i pernilongo poden ser dignes d'atenció. El substantiu perna conté una e oberta i aquesta vocal es manté en els compostos (Regueira, 2010). Si el primer element fos àton, apareixeria una $e$ tancada. En espanyol veiem el caràcter àton del primer element en corniaberto, conialto, etc., perquè apareix la vocal o i no el diftong ue (cuerno). En canvi, en cuellicorto, cuellierguido, etc. i pierniabierto, piernicorto, etc. hi ha un diftong, per tant aquest criteri produeix resultats ambigus. És a dir, si observem les tres llengües en què hi ha un element d'enllaç, el resultat no indica clarament si el primer element és àton. El que sí que sembla sistemàtic és que en català, on no hi ha vocal d'enllaç, el primer element és tònic i no es produeix reducció vocàlica, p. ex. bocafi, camacoix, capalt, etc. (Bruguera, 2004, DCVB 1930-1962).

\section{Referències bibliogràfiques}

Academia das Ciências de Lisboa (2001). Dicionário da Lingua Portuguesa Contemporânea (DLPC). Lisboa: Verbo.

Aguirre, Carmen (2013). Manual de morfología. Barcelona: Castalia.

Alcover, Antoni Maria - Moll, Francesc de Borja (1930-1962). Diccionari català-valenciàbalear (DCVB). Palma: Moll.

Bruguera, Jordi (2004). Diccionari ortogräfic i de pronúncia. Barcelona: Enciclopèdia Catalana.

Bruguera, Jordi (2006). Diccionari de la formació de mots. Barcelona: Enciclopèdia Catalana.

Gràcia, Lluïsa (2002). Formació de mots: composició. Dins: Solà, Joan - Lloret, Maria Rosa - Mascaró, Joan - Pérez Saldanya, Manuel (orgs.). Gramàtica del català contemporani, vol. I. Barcelona: Editorial Empúries. 781-829.

Gran diccionario Xerais da lingua (2000). Vigo: Edicións Xerais de Galicia.

Institut d'Estudis Catalans (2007). Diccionari de la llengua catalana. Barcelona: Edicions 62 / Enciclopèdia Catalana.

Lang, Mervyn F. (1992). Formación de palabras en español. Madrid: Cátedra.

Regueira, Xosé Luis (2010). Dicionario de pronuncia da lingua galega. A Coruña: Instituto da Lingua Galega / Real Academia Galega.

Seco, Manuel - Andrés, Olimpia - Ramos, Gabino (2000). Diccionario abreviado del español actual. Madrid: Grupo Santillana de Ediciones.

Val Álvaro, José Francisco (1999). La composición. Dins: Bosque, Ignacio - Demonte, Violeta (orgs.). Gramática descriptiva de la lengua española, Madrid: Espasa Calpe. 4757-4841. 